\title{
Endoskopik Retrograd Kolanjiopankreatografi İşleminde Sedasyon Uygulamalarında Ramsey Sedasyon Skalası ile Bispektral İndeks Monitörizasyonunun Karşılaştırılması
}

\author{
Comparing the Application of Sedation with Ramsey Sedation Scale versus Bispectral Index \\ Monitoring During Endoscopic Retrograde Cholangiopancreatography Procedures
}

\author{
Nagihan POLAT' ${ }^{1}$, Yüksel ELA', Serdar KOKULU' ${ }^{1}$, Elif Doğan BAKi', \\ Sezgin YILMAZ ${ }^{2}$, Remziye Gül SIVACI ${ }^{1}$ \\ 'Afyon Kocatepe Üniversitesi Tıp Fakültesi, Anesteziyoloji ve Reanimasyon AD, Afyonkarahisar. \\ ${ }^{2}$ Afyon Kocatepe Üniversitesi Tıp Fakültesi, Genel Cerrahi AD, Afyonkarahisar \\ Geliş Tarihi / Received: 19.12.2013 \\ Kabul Tarihi / Accepted: 14.04.2014
}

\begin{abstract}
ÖZET
Amaç: Endoskopik retrograd kolanjiopankreatografi (ERKP) pankreas, safra kesesi ve karaciğerin drenajını sağlayan kanalların görüntülenmesi işlemidir. Bu işlem esnasında bilinçli sedasyon amacıyla propofol sıklıkla kullanılmaktadır. Bu çalışmamızda, ERKP işlemi esnasında propofolle uygulanan hekim kontrollü sedasyon ile bispektral indeks kontrollü sedasyonu (BIS) karşılaştırmayı amaçladık.
\end{abstract}

Gereç ve Yöntem: 18-75 yaşları arasında, 60 olgu çalışmaya alındı. Hastalar rastgele iki gruba ayrıldıktan sonra grup 1 hastalara ramsey sedasyon skalası 3-4 olacak şekilde hekim tarafından propofol aralıklı bolus dozlar şeklinde verildi. Grup 2 hastalara ise BiS değeri 60-85 arasında olacak şekilde propofol bolus dozlar uygulandı. Hastaların her 5 dakikada bir SpO2, sistolik, diastolik ve ortalama kan basınçları, kalp atım hızı, komplikasyonlar ve yan etkiler, işlem süresi, hastanın uyanıklık durumu kaydedildi.

Bulgular: Her iki grupta demografik veriler arasında anlamlı bir fark yoktu. Hastaların vital bulguları benzerdi. Gruplar arasında komplikasyonlar açısından istatistiksel olarak anlamlı fark bulunmadı. Her iki gruba bakıldığında ortalama işlem süreleri birbirlerine yakınken, hastaların derlenme süresi BiS kontrollü grupta anlamlı olarak daha kısa tespit edildi.

Sonuç: ERKP esnasında uygulanan sedasyonda, bisipektral indeks monitörizasyonu hekim kontrollü sedasyon kadar güvenlidir.

Anahtar Kelimeler: Endoskopik retrograd kolanjiopankreatografi, bispektral indeks, propofol, sedasyon.

\section{ABSTRACT}

Objective: Endoscopic retrograde cholangiopancreatography (ERCP) is the process of displaying channels that provide pancreas, gall bladder and liver drainage Propofol is often used for conscious sedation during this procedure. In this study we aimed to compare the physician controlled sedation with propofol versus bispectral index controlled sedation (BIS) during ERCP.

Material and Methods: 60 patients aged between 18 and 75 were enrolled in this study. Patients were divided randomly into two groups; Group 1 patients were administered intermittent doses of propofol to provide Ramsey Sedation Scale 3-4 by the physician monitorization whether Group 2 patients were given intermittent doses of propofol to maintain the BIS level between 60 and 85 . SPO2, systolic, diastolic and, mean blood pressures, heart rates, complications, adverse effects, duration of operation, patient awakeness were recorded five minutes periodically.

Results: There was no statistically significant difference between the groups in terms of demographic characteristics. Patients' hemodynamic data were similar too. There was no statistically significance in terms of complications between the groups. Both groups were close to each other considering the average processing time whether recovery time of patients in the BIS group was detected significantly shorter than the Ramsey group.

Conclusion: Application of sedation with BIS is as safe as physician-controlled sedation in ERCP.

Keywords: Endoscopic retrograde cholangiopancreatography, bispektral index, propofol, sedation. 


\section{GíRiş}

ERKP, kontrast madde verilerek duodenoskop ve röntgen ışınları yardımıyla, pankreas, safra kesesi ve karaciğerin drenajını sağlayan kanalların görüntülenmesi işlemidir. Endoskopik olarak ampulla vateri görüntülenerek, ortak kanal kanülize edilir. ERKP, endoskopik sfinkteretomi, koledoktan taş ekstrasyonu, malign ve benign biliyer strüktürlerde stent uygulaması ve biyopsi alınması amacıyla da kullanılmaktadır böylelikle pankreatikobiliyer patolojilerin hem teşhis hem de tedavisinde çok önemli bir yere sahiptir (1).

BiS, elektroensefalogram verilerini esas alarak anestezi derinliğin sayısallaştıran bir yorum yöntemidir (2). Anestezi derinliğini ölçmede kullanılan Bis, kortikal derin yapılardaki aktiviteyi göstermektedir. BiS, genellikle yoğun bakım ünitelerinde mekanik ventilasyonla takip edilen hastalara uygulanan veya rejyonel anestezi ile birlikte uygulanan sedasyonun derinliğini ölçmede kullanılan noninvaziv bir metottur (3-6).

Biz bu çalışmamızda; ERKP sırasında profolle uygulanan sedasyon işlemlerinde Bis monitörizasyonunun hekim gözlemiyle uygulanan sedasyon işlemlerine güvenli bir alternatif olup olamayacağını araştırmak istedik.

\section{GEREÇ ve YÖNTEM}

Hastanemiz yerel etik kurundan onay (2013/0421) alındıktan sonra, prospektif ve randomize olarak planlanan çalışmamıza ERKP için sedasyon uygulanacak 60 olgu dahil edildi.

Araştırmamızda hastanemiz genel cerrahi kliniğinde ERKP yapılması planlanan 18-75 yaş arası Amerikan Anestezistler Birliği'nin (ASA) sınıflamasına göre ASA 1-3 olan hastalar dahil edildi. Tüm hastalar işlem hakkında bilgilendirildi ve yazılı onamları alındı.

İletişimde zorluk çekilen (dil problemi, sağırlık gibi), kullanılan ilaçlara alerjisi olan, kontrolsüz yandaş hastalığı (diabetes mellitus, hipertansiyon ve benzeri), karaciğer veya böbrek yetmezliği, psikiyatrik bozukluğu, uzun süre opioid kullanımı, alkol kullanım hikayesi, hamilelik şüphesi veya gebe olan olgular çalışma dışı bırakıldılar.
Girişim öncesi premedikasyon uygulanmayan olgulara, noninvaziv arteryel basınç monitörizasyonu, periferik oksijen saturasyonu (SpO2) ve kalp atım hızı (KAH) monitörizasyonu yapıldı. Sağ veya sol antekubital bölgeden 20 gauge intravenöz kateter yerleştirildi. \% $0.9^{\prime}$ luk $\mathrm{NaCl}$ (100 cc /saat) infüzyonu yapıldı. Tüm olgulara işlem boyunca maske ile 4 lt/dk oksijen verildi. Hastalar her bir grupda 30 hasta olacak şekilde rastgele iki gruba ayrıldı. Grup 1 hastalara Ramsey sedasyon skalası 3-4 olacak şekilde hekim tarafından aralıklı bolus dozlar şeklinde propofol verildi. Grup 2 hastalara noninvaziv bir işlem olan BiS elektrodu bağlandı. BiS değeri 60-85 arasında olacak şekilde propofol bolus dozlar halinde uygulandı. Hastaların her 5 dakikada bir SpO2 sistolik kan basıncı (SKB), diastolik kan basıncı (DKB) ve ortalama kan basınçları (OKB), $\mathrm{KAH}$, komplikasyonlar ve yan etkiler, işlem süresi, hastanın uyanıklık durumu kaydedildi.

Hastaların derlenmesinin kontrolü için Modifiye Aldrete Skoru (MAS) kullanıldı. MAS 9-10 olan hastalar derlenme ünitesinden çıkarıldı.

Tüm olguların vital parametreleri, yükleme dozu öncesi ve sonrası, girişim süresince her 5 dakikada bir kaydedildi. SpO2'nin \% 92'nin altına 10 saniyeden daha fazla düşmesi oksijen desatürasyonu, KAH'nın dakikada 50'nin altına düşmesi veya baz değerden \% 20 azalması bradikardi, KAH'nın 110'un üzerine çıkması veya baz değerden \% 20 artması taşikardi, OAB'nın 60 mmHg'nın altına düşmesi veya baz değerden \% 20 azalması hipotansiyon olarak değerlendirildi $(7,8)$. Solunum depresyonu, alerji, öksürme, öğürme, bulantı ve kusma gibi komplikasyonlar kayıt edildi.

Çalışmanın analizinde SPSS Windows 18.0 programı kullanıldı. Tanımlayıcı analizler ortalama ve standart sapmalar kullanılarak verildi. Değişkenlerin normal dağılıma uygunluğu incelendi. Sürekli değişkenlerin karşılaştırılmasında normal dağılıma uymadığı için, analizlerde Mann-Whitney $U$ testi kullanıldı. Kategorik değer alan değişkenler yüzde olarak ifade edildi ve gruplar arası karşılaştırmalarında Ki-kare testi kullanıldı. Değerlendirme sonuçları, $p<0.05$ olduğunda istatiksel olarak anlamlı kabul edildi. 


\section{BULGULAR}

Her iki gruptaki hastalar yaş, vücut ağırlığı ve ASA değerleri açısından karşılaştırıldıkların da istatiksel olarak fark yoktu (Tablo I).

Her iki grubun OKB karşılaştırılmasında 5, 10, $15,20,25,35,40,45,50,55,60$. dakikalarda istatistiksel olarak anlamlı bir fark olmadığı saptandı. Ancak 30. dakikadaki p değeri 0,019 $(p<0,05)$ olarak bulundu ve anlamlı bir fark olduğu görüldü (Şekil I).

Her iki grubun SPO2 değerlerinin karşılaştırılmasında 5, 10, 25, 35, 40,45, 50, 55, 60. dakikalarda istatistiksel olarak anlamlı bir fark saptanmadı. Ancak 15. dakikadaki p değeri 0,013, 20. dakikadaki $p$ değeri $0,019,30$. dakikadaki p değeri 0,026 olarak saptandı ve bu anlardaki değerlendirmeler istatistiki olarak anlamlıydı (Şekil II) $(p<0,05)$.

Gruplar arasında komplikasyonlar açısından istatistiksel olarak anlamlı fark bulunmadı (Tablo II).
Her iki gruba bakıldığında ortalama işlem süreleri birbirlerine yakınken ( $p>0,05)$, hastaların derlenme süresi BiS kontrollü grupta istatistiki anlamlı olarak daha kısa tespit edildi $(p<0,05)$.

\section{TARTIŞMA}

Pankreatikobiliyer patolojilerin tanı ve tedavi aşamasında ERKP çok önemli bir role sahiptir. Oral yoldan endoskop aracılığıyla gerçekleştirilir. ERKP işlemi sedasyonsuz yapıldığı zaman son derece ağrılı ve rahatsız edicidir (9).

ERKP işlemi esnasında sedasyon uygulanarak, hareketsizlik ve yeterli analjezinin sağlanması, öksürük, öğürme ve bulantıdan kaçınılması ve koruyucu havayolu reflekslerinin baskılanmamış olması arzu edilir. Bu nedenle kullanılacak olan sedasyon ilacının dozu iyi titre edilmeli ve monitörizasyonu yöntemleri ile hasta yakın takip edilmelidir (10).

Zacny ve ark., sağlıklı gönüllülerde yaptıkları çalışmalarında propofol infüzyonuna ait psikomotor etkilerini incelemişler; sedasyon, amnezi, hızlı ve tam derlenme özellikleri ile propofolün günübirlik cerrahi için uygun bir ajan olduğunu belirtmişlerdir (11).

Tablo I: Hastaların demografik ve ASA verileri.

\begin{tabular}{|l|l|l|l|}
\hline & $\begin{array}{l}\text { Hekim Kontrollü Grup } \\
\mathbf{n = 3 0}\end{array}$ & $\begin{array}{l}\text { BiS Kontrollü Grup } \\
\mathbf{n = 3 0}\end{array}$ & $\mathbf{p}$ \\
\hline Yaş (Yıl) & $58,70 \pm 2,05$ & $56,23 \pm 2,47$ & 0,464 \\
\hline Ağırlık (kg) & $77,73 \pm 3,16$ & $73,07 \pm 2,28$ & 0,275 \\
\hline ASA & $2 \pm 0,117$ & $1,80 \pm 0,117$ & 0,224 \\
\hline Anti-HIV & $14.874(9.245 / 5.629)$ & $1(0 / 1)$ & 0,007 \\
\hline
\end{tabular}

ASA: Amerikan anestezistler birliği, Bis: Bispekral indeks.

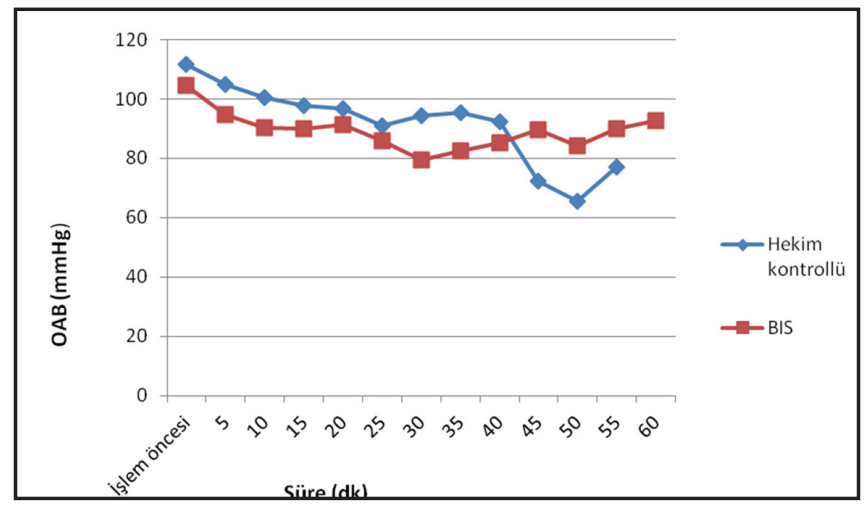

Şekil I: Ortalama Arter Basıncı (OAB) değerlerinin gruplara göre dağılımı. 
Tablo II: Komplikasyonların gruplara göre dağılımı.

\begin{tabular}{|c|c|c|c|c|}
\hline & & $\begin{array}{l}\text { Hekim Kontrollü } \\
\text { Grup } n=30\end{array}$ & $\begin{array}{l}\text { Bis Kontrollü } \\
\text { Grup } \quad n=30\end{array}$ & Toplam \\
\hline \multirow[t]{4}{*}{ Apne } & Sayı & 1 & 1 & 2 \\
\hline & $\%$ komplikasyon & $\% 50$ & $\% 50$ & $\% 100$ \\
\hline & $\%$ grup & $\% 3,3$ & $\% 3,3$ & $\% 3,3$ \\
\hline & $\%$ total & $\% 1,7$ & $\% 1,7$ & $\% 3,3$ \\
\hline \multirow[t]{4}{*}{ Hipertansiyon } & Sayı & 3 & 4 & 7 \\
\hline & \% komplikasyon & $\% 42,9$ & $\% 57,1$ & $\% 100$ \\
\hline & $\%$ grup & $\% 10$ & $\% 13,3$ & $\% 11,7$ \\
\hline & $\%$ total & $\% 5$ & $\% 6,7$ & $\% 11,7$ \\
\hline \multirow[t]{4}{*}{ Taşikardi } & Sayı & 13 & 8 & 21 \\
\hline & \% komplikasyon & $\% 61,9$ & $\% 38,1$ & $\% 100$ \\
\hline & $\%$ grup & $\% 43,3$ & $\% 26,7$ & $\% 35$ \\
\hline & $\%$ total & $\% 21,7$ & $\% 13,3$ & $\% 35$ \\
\hline \multirow[t]{4}{*}{ Yok } & Sayı & 5 & 9 & 14 \\
\hline & $\%$ komplikasyon & $\% 35,7$ & $\% 64,3$ & $\% 100$ \\
\hline & $\%$ grup & $\% 16,7$ & $\% 30$ & $\% 23,3$ \\
\hline & $\%$ total & $\% 8,3$ & $\% 15$ & $\% 23,3$ \\
\hline
\end{tabular}

Bis:Bispektral indeks

Propofol, günümüzde erişkin ve çocukların anestezi indüksiyon ve idamesi ile sedasyon uygulamalarında yaygın olarak kullanılmaktadır (12-15). Bizde bu çalışmamızda günübirlik bir işlem olması ve derlenmenin hızlı sağlanması amaciyla propofolü tercih ettik.

Sedasyonun kardiyovasküler ve solunum sistemine istenmeyen etkiler oluşabilir. Bu nedenle hastaların noninvaziv kan basınçları, elektro kardiyografi, $\mathrm{SpO} 2$ ve solunum sayıları yakından takip edilmelidir $(16,17)$. Çalışmamızda da olgularımızın vital bulguları işlem boyunca ve derlenme ünitesinde monitörize edildi.

BiS kullanımının yararları; uyanma riskinin azalması, kişisel ihtiyaçlara göre hipnotik ilaç verilebilmesi, aşırı veya yetersiz doz ilaç verme ihtimalinin azalması, daha hızlı derlenme sağlamasıdır. Anestezi derinliğini ölçmede Bís monitörizasyonunun sensitivitesi \% 97,3, spesifitesi ise $\% 94,4^{\prime}$ dür. (18).

Guignard ve ark., ağrılı uyaranlara karşı $\mathrm{KAH}$ ve $O A B$ değişiklikleri göstermeyen hastalarda anestezi derinliğinin takibinde BiS monitörizasyonunun daha güvenli bir yöntem olduğunu bildirmişlerdir (19). Kussmann ve ark. ise BiS ile hemodinamik parametreler arasında bir ilişki gösterememişlerdir (20). Bizim çalışmamızda da BiS değerlerinin değişkenliğiyle hemodinamik parametrelerdeki değişiklikler arası anlamlı bir bulgu saptanmadı. (Şekil I ve II)

Çalışmada gruplar erken derlenme açısından karşılaştırıldığında BiS kontrol grubunda istatistiksel olarak belirgin fark gözlenmiştir. BiS kontrollü grupta hekim kontrollü gruba göre daha hızlı derlenme olduğu saptanmıştır. Ancak literatürde yapılan çalışmalarda kognitif fonksiyonlar genellikle genel anestezi sonrası olgularda değerlendirilmiş olup, bizim çalışmamızda günübirlik anestezide sedasyon sonrası değerlendirilmiştir. Bize göre Bís kontrollü grupta daha erken derlenme saptanmasının nedeni; hekim kontrollü grupta hasta konforunun ön planda tutularak ilaç uygulamasının daha sık yapılması, derlenmenin bu grupta daha geç olmasına neden olmuştur.

Biz bu çalışmamızda; ERCP sırasında profolle uygulanan sedasyon işlemlerinde Bis monitorizasyonunun hekim gözlemiyle uygulanan sedasyon işlemlerine güvenli bir alternatif olup olamayacağını araştırmak istedik.

Tüm bu sonuçları topladığımızda BiS monitörizasyonunun ERKP için propofolle uygulanan sedasyonda; hekim kontrollü sedasyon kadar güvenli, hasta konforu ve işlem konforu açısından 


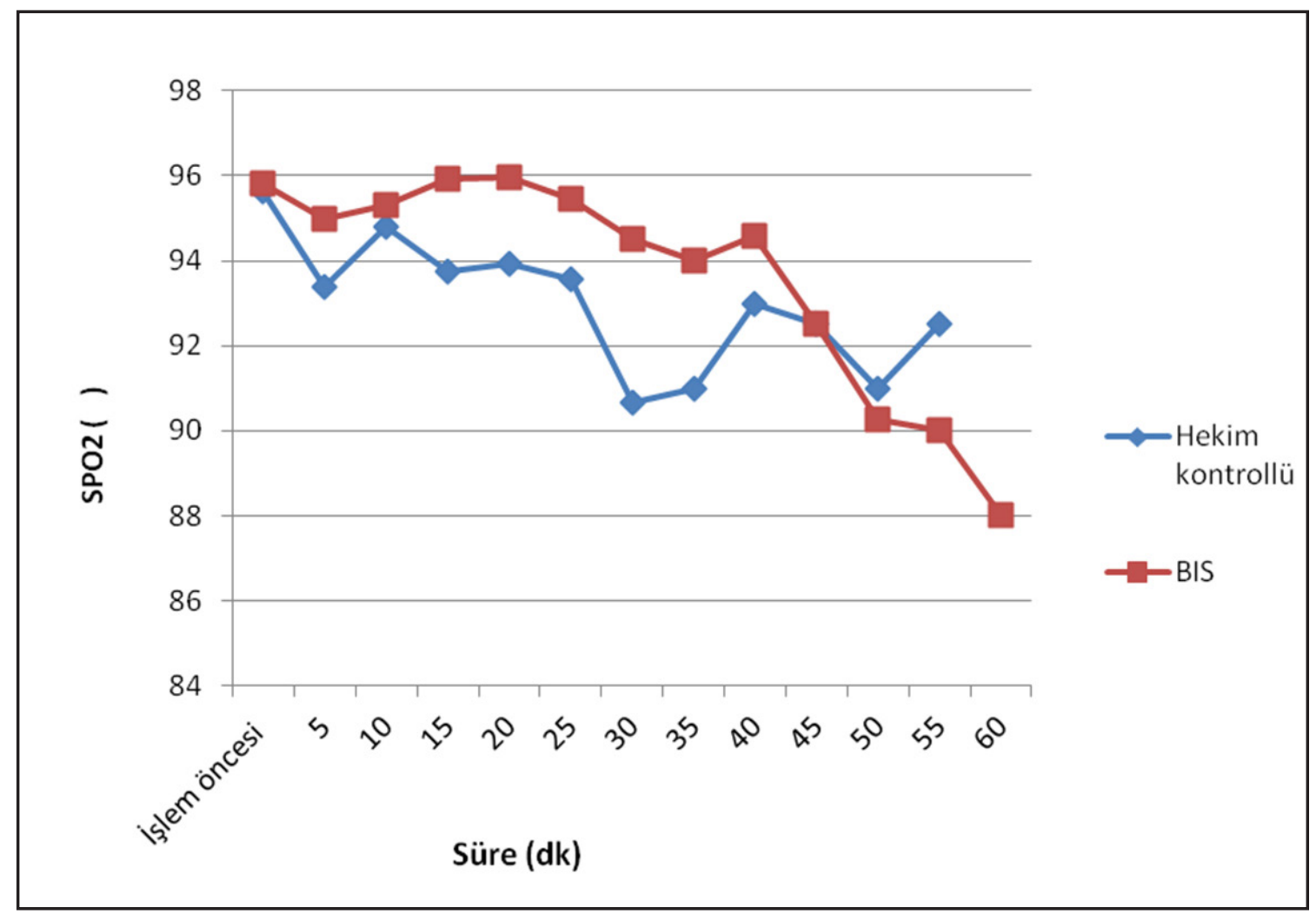

Şekil II: Oksijen Saturasyonu (SpO2) değerlerinin gruplara göre dağılımı.

değerli bir uygulama tekniği olduğu sonucuna vardık. BíS kontrollü grubun bu sonuçlara göre daha az ilaç kullanımı, daha hızı derlenmesi ve komplikasyon açısından farklılık göstermemesi bu grubun pozitif yönlerini öne çıkarsa da; kullandığımız BiS elektrodunun maliyetinin işlem maliyetini oldukça artırması da en önemli negatif yönü olduğunu düşünmekteyiz.

\section{KAYNAKLAR}

1. Turan M, Karadayı K, Duman M, ve ark. Endoskopik retrograd kolanjiopankreatografi (ERKP) deneyimimiz. CÜ Tıp Fakültesi Dergisi 2003;25(4):171-6.

2. Balcı C, Sıvacı RG, Saka O, Akbulut G. Desfluran ve sevofluranın derlenme sürelerinin bispektral indeks değerleri ile karşılaştırılması. Anestezi Dergisi 2006;14(1):32-6.

3. Ma PL, Zhao JZ, Su JW, Li Q, Wang Y. Comparison of reliability of BIS and sedation - agitation scale in assesing the depth of sedation in patients treated with mechanical ventilation. Zhonguo Wei Zhong Bing Ji Jiu Yi Xue 2006;18(6):323-6.
4. Consales G, Chelazzi C, Rinaldi S, De Gaudio AR. BIS compared to ramsay score for sedation monitoring in intensive care ünits. Minerva Anestesiol 2006:72(5):329-36.

5. Ball J. How useful is the BIS in the management of ICU patients. Minerva Anestesiol 2002:68(4):248-51.

6. Koç H, Erk G, Apaydın Y, Horasanlı E, Yiğitbaşı B, Dikmen B. Epidural anestezi ile herni operasyonu uygulanan hastalarda klasik türk müziğinin intraoperatif sedasyon üzerine etkileri. Türk Anesteziyoloji ve Reananimasyon Derneği Dergisi 2009;37(6):366-73.

7. Lui S, Chiu AA, Carpenter RL, et al. Fentanyl prolongs lidocaine spinal anesthesia without prolonging recovery. Anesth Analg 1995;80(4):730-4.

8. Göksu $S$, Arık H, Demiryürek $S$, et al. Effect of dexmedetomidine infusion in patients undergoing $f$ unctional endoscopic sinus surgery under local anaesthesia. Eur J Anaesthesiol 2007;7(1):1-7. 
9. Riphaus A, Stergiou N, Wehrmann T. Sedation with propofol for routine ERCP in high-risk octogenarians: a randomized,controlled study. Am J Gastroenterol 2005;100(9):1957-63.

10. Demiraran $Y$, Korkut E, Tamer A, et al. The comparison of dexmedetomidine and midazolam used for sedation of patients during upper endoscopy: a prospective, randomized study. Can J Gastroenterol 2007;21(1):25-9.

11. Zacny JP, Lichtor JL, Coalson DW, et al. Subjective and psychomotor effects of subanesthetic doses of propofol in heal thy volunteers. Anesthesiology 1992;76(5):696-702.

12. Reves JG, Glass PSA, Lubarsky DA. Anesthesia. In: Miller RD. Intravenous nonopioid anesthetics. 6th Edition. New York: Churchill Livingstone, 2005:317-79.

13. Camu F. Moderm anesthetic. In: Jürgen $S$, Helmut S. Modern intravenous anesthetic. 2th Edition. Berlin: Heideberg, 2004;363-77.

14. White $P$, Romero G. Clinical anesthesia. In: Barash PG, Cullen BF, Stoelting RK. Nonopioid intravenous anestesia. 5th Edition. Philadelphia: Lipincott Williams and Wilkins, 2006;33452.

15. Benedict P,Tremper K. Anesthesiology. In: Longnecker D, Brown D. The anesthetic plan for healthy patients. 1th Edition. Pennsylvania: The Mcgraw-Hill Company, 2008;68-87.

16. Prielipp RC, Wall MH, Tobin JR, et al. Dexmedetomidine-induced sedation in volunteers decreases regional and global cerebral blood flow. Anesth Analg 2002;95(4):1052-9.

17. İyilikçi L, Çakmak Ş, Ögdül E, ve ark. Ameliyathane dışı anestezi uygulamalarında deneyimlerimiz . Türk Anesteziyoloji Reanimasyon Derneği Dergisi 2006;34(3):169-76.

18. Sleigh JW, Donovan J. Comparison of bispectral index, 95\% spectral edge frequency and approximate entropy of the EEG, with changes in heart rate variability during induction of general anaesthe sia. Br J Anaesth 1999;82(5):66671.
19. Guignard B, Menigaux C, Dupont $X$, et al. The effect of remifentanil on the bispectral index change and hemodynamic responses after orotracheal intubation. Anesth Analg 2000;90(1):161-7.

20. Kussman BD, Gruber EM, Zurakowski D, et al. Bispectral index monitoring during infant cardiac surgery: relationship of BIS to the stress response and plasma fentanyl levels. Paediatr Anaesth 2001;11(6):663-9. 